\title{
Human Papillomavirus-Positive Squamous Cell Carcinoma of the Tonsil: Case Report
}

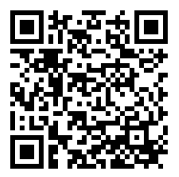

\author{
H Ardhaoui, S Halily*, S Rouadi, R Abada, M Roubal and M Mahtar \\ Department of Oto-Rhino-Laryngology, Head and Neck Surgery, University Hospital, Morocco
}

Submission: December 1, 2019; Published: December 18, 2019

*Corresponding author: H Ardhaoui, Department of Oto-Rhino-Laryngology, Head and Neck Surgery, University Hospital, Casablanca, Morocco

\begin{abstract}
The association of squamous cell carcinoma and HPV is increasing especially among young non-smoker males. This fact is likely due to changing sexual behaviors. The main concern of this disease is the high percentage of recurrence especially when the treatment is not well established. We report a case of a human papillomavirus-positive squamous cell carcinoma of the left tonsil without recurrence after 5 years.

The objective of this study is to describe - from our clinical case and literature review- the clinical and radiological features of human papillomavirus-positive squamous cell carcinoma of the tonsil and discuss its therapeutic management and prognosis.

Keywords: Human papilloma virus; Squamous cell carcinoma; Tonsil
\end{abstract}

\section{Introduction}

It is agreed that oro-pharyngeal cancers (OPCs) emerge from two main factors: alcohol and tobacco use, and human papilloma virus (HPV) infection, especially HPV16 [1-4]. The most common site is the lingual and palatine tonsils [5]. The association squamous cell carcinoma and HPV is increasing especially among younger non-smoker males. This is likely due to changing sexual behaviors [2]. It is also reported that this association has a better response to therapy and overall survival [4].

\section{Case Report}

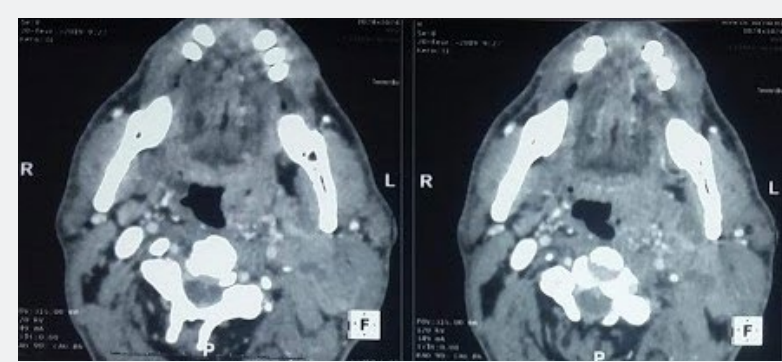

Figure 1: Axial CT scan showing a mass of the left tonsil with enlarged level II lymph nodes.

A 55-year-old male with no medical history or toxic habits consulted the otolaryngology clinic for a left cervical adenopathy evolving for four months without other associated signs. Physical examination revealed an ulcerated mass in the left palatine tonsil and multiple lymphadenopathies at level II of the same side.
Laryngoscopy showed a fungating ulcerated mass of the left tonsil without invasion of the lingual surface of the epiglottis. Base of tongue, larynx, esophagus and the rest of the pharynx were free of any suspicious mass. Pathology revealed a tonsillar papilloma colonized by squamous cell carcinoma.

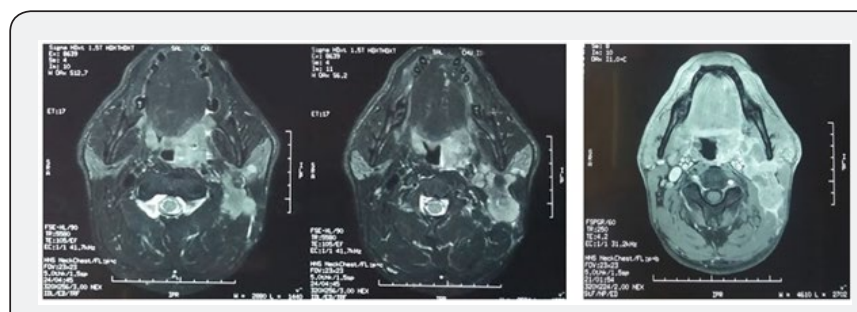

Figure 2: Axial MRI showing the mass of the left tonsil.

Contrast-enhanced computed tomography (CT) and magnetic resonance imaging (MRI) scans of the head and neck showed a $41 \times 25 \times 60 \mathrm{~mm}$ mass in the left palatine tonsil. This process extends to the base of the tongue, glosso-epiglottic, pharyngoepiglottic and ary-epiglottic folds, left para-pharyngeal fat and the retro-pharyngeal space. It also showed multiple necrotic left cervical lymphadenopathies; the largest of which measures 19.8 x $26.7 \mathrm{~mm}$ (left IIa level) (Figures 1-3). A whole-body positron emission tomography-computed tomography (PET-CT) did not show metastasis outside of fluorodeoxyglucose uptake within the left palatine tonsil and left level II lymph nodes. 


\section{Global Journal of Otolaryngology}

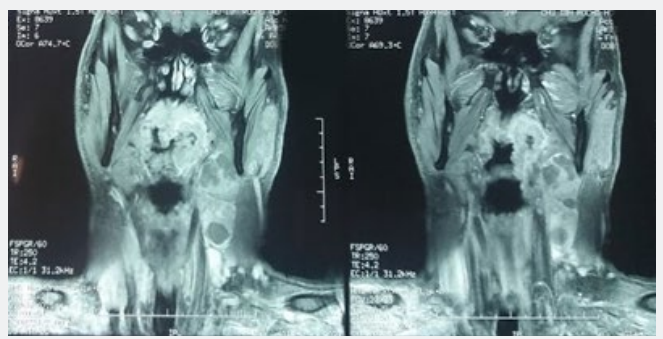

Figure 3: Coronal MRI, showing tumor of the left tonsil and ipsilateral lymph nodes Ila.

The patient underwent an enlarged left tonsillectomy, with contralateral tonsillectomy and left triangular neck dissection. HPV infection was detected in the specimen. He also received postoperative radiotherapy with a dosage of 60 Gray in 30 fractions and two cycles of adjuvant chemotherapy with a regimen of CDDP (30 mg/m2, days 1 and 15) and irinotecan (CPT-11) (60 $\mathrm{mg} / \mathrm{m} 2$, days 1 and 15 ) at four weeks intervals. The evolution was good without recurrence after five years.

\section{Discussion}

Human papillomavirus-positive head and neck squamous cell carcinoma (HNSCC) is a major world health problem with 50000 new cases per year and 11000 deaths expected annually in the United States alone [6]. In the USA, in $90 \%$ of oropharyngeal SCC, subtype 16 was detected which is sexually transmitted. It is well known that HPV subtypes 16, 18, 33 and 35 induce oropharyngeal SCC yet it is associated with a better prognosis than other SCCs [7]. However, the main concern is local and lymph node recurrence [8]. Local extension of tonsillar region tumors ranges between 27 and $77 \%$. It proceeds by invasion of underlying muscle fibers; mainly pharyngeal constrictor muscles, palatoglossus and palatopharyngeus muscles $[9,10]$. Lymph node involvement was noted in $26.2 \%$ of cases on histology in Laccourreye's study [11].

In 2012, the French society of otolarynglogy considered that CT scan was the gold standard for local extension assessment in oropharyngeal cancer [12]. However, Gadolinium-enhanced T1- weighted MRI sequences provide more precise evaluation of invasion of oropharyngeal tissues, both mucosal and muscular, with fine analysis of the parapharyngeal space and styloglossus muscle, while T2-weighted sequences allow lymph-node assessment. It became the main imaging technique for local assessment of tonsillar region cancer [13].

Despite a multimodal treatment including surgical resection, radiotherapy, and chemotherapy, most cases of HNSCC develop distant metastasis in the follow-up periods. It is recommended to include HPV status in initial assessment of HNSCC, owing to the significantly greater survival, to optimize treatment [14]. The prevalence of synchronous bilateral HNSCC of the tonsil is still unknown, and much controversy regarding routinely removing the contralateral tonsil [15]. Performing a routine contralateral tonsillectomy is explained by the potentially fatal consequences of missing an occult contralateral disease. Moreover, symmetric appearance of the palatal arches improves clinical follow-up and makes detection of tumor recurrence easier without a significant increase in morbidity [15-17].

It is intriguing that the addition of either chemotherapy (typically Cisplatin) or the EGFR targeting monoclonal antibody Cetuximab to radical radiotherapy in the treatment of HPV undetermined tumors historically improves overall survival by $10 \%$ [18]. As there is evidence of a relationship between EGFR expression and HPV as measured by p16. On the other hand, it was recently proven that tonsillectomy prior to radiation therapy was beneficial. An American study of 524 patients with earlystage tonsillar SCC noted that 5-year overall and recurrence-free survival after radiation therapy varied significantly; respectively $83 \%$ and $69 \%$ with prior tonsillectomy and $64 \%$ and $76 \%$ without tonsillectomy [19].

\section{Conclusion}

The incidence of HPV-associated oropharyngeal cancers is increasing. The main concern of this disease is the high percentage of recurrence especially when the treatment is not well established.

\section{References}

1. Mehanna H, Beech T, Nicholson T, et al. (2013) Prevalence of human papillomavirus in oropharyngeal and nonoropharyngeal head and neck cancer-systematic review and meta-analysis of trends by time and region. Head Neck 35: 747-755.

2. Gillison ML, D'Souza G, Westra W, et al. (2008) Distinct risk factor profiles for human papillomavirus type 16-positive and human papillomavirus type 16-negative head and neck cancers. J Natl Cancer Inst 100: 407-420.

3. Chaturvedi AK, Engels EA, Pfeiffer RM, et al. (2011) Human papillomavirus and rising oropharyngeal cancer incidence in the United States. J Clin Oncol 29: 4294-4301.

4. Masterson L, Moualed D, Liu ZW, et al. (2014) De-escalation treatment protocols for human papilloma virus-associated oropharyngeal squamous cell carcinoma: a systematic review and meta-analysis of current clinical trials. Eur J Cancer 50: 2636-2648.

5. El-Naggar AK, Westra WH (2012) p16 expression as a surrogate marker for HPV-related oropharyngeal carcinoma: a guide for interpretative relevance and consistency. Head Neck 34: 459-461.

6. Siegel R, Naishadham D, Jemal A (2013) Cancer statistics, 2013. Ca Cancer J Clin 63: 11-30.

7. Guo T, Eisele DW, Fakhry C (2016) The potential impact of prophylactic human papillomavirus vaccination on oropharyngeal cancer. Cancer 122: 2313-2323.

8. Vergez S, Morinière S, Dubrulle F, et al (2013) Initial staging of squamous cell carcinoma of the oral cavity, larynx and pharynx (excluding nasopharynx). Part I: locoregional extension assessment: 2012 SFORL guidelines. Eur Ann Otorhinolaryngol Head Neck Dis 130: $39-45$. 
9. Lee J, Yoon N, Choi SY (2013) Extent of local invasion and safe resection in cT1-2 tonsil cancer. J Surg Oncol 107: 469-73.

10. Park JO, Lee YS, Joo YH, Nam IC, Cho KJ, et al. (2012) Can the transoral approach secure a cancer-free deep margin in tonsil cancer? Oral Oncol 48: 658-661.

11. Laccourreye O, Malinvaud D, Alzahrani H, et al. (2013) Conventional transoral surgery for stage I-II squamous cell carcinoma of the tonsillar region. Head Neck 35: 653-659.

12. Vergez S, Morinière S, Dubrulle F, et al. (2013) Initial staging of squamous cell carcinoma of the oral cavity, larynx and pharynx (excluding nasopharynx). Part I: locoregional extension assessment: 2012 SFORL guidelines. Eur Ann Otorhinolaryngol Head Neck Dis 130 39-45.

13. Eddine CA, Piekarski JD, Benamor M (2008) Tumors of the oropharynx and oral cavity: MR, CT, PET-CT imaging. J Radiol 89: 968-983.

14. Badoual C, Righini C, Barry B, et al. (2012) Pre-therapeutic histological and cytological assessment in head and neck squamous cell carcinomas. French Society of Otorhinolaryngology Guidelines - 2012 Eur Ann Otorhinolaryngol Head Neck Dis 129: 319-326.
15. Patel AB, Hinni ML, Pollei TR, et al. (2015) Severe prolonged dysphagia following transoral resection of bilateral synchronous tonsillar carcinoma. Eur Arch Otorhinolaryngol 272: 3585-3591.

16. Dziegielewski PT, Boyce BJ, Old M, et al. (2017) Transoral robotic surgery for tonsillar cancer: addressing the contralateral tonsil. Head Neck 39: 2224-2231.

17. Theodoraki MN, Veit JA, Hoffmann TK, Greve J (2017) Synchronous bilateral tonsil carcinoma: case presentation and review of the literature. Infect Agent Cancer 12: 38.

18. Bonner JA, Harari PM, Giralt J, et al. (2006) Radiotherapy plus cetuximab for squamous-cell carcinoma of the head and neck. $\mathrm{N}$ Engl J Med 354(6): 567-578.

19. HollidayMA, TavalucR, Zhuang T,WangH, DavidsonB (2013) Oncologic benefit oftonsillectomy in stage I and II tonsil cancer: a surveillance epidemiology and end results database review. JAMA Otolaryngol Head Neck Surg 139: 362-366.

\begin{tabular}{l} 
Your next submission with Juniper Publishers \\
will reach you the below assets \\
- Quality Editorial service \\
- Swift Peer Review \\
- Reprints availability \\
- E-prints Service \\
- Manuscript Podcast for convenient understanding \\
- Global attainment for your research \\
- Manuscript accessibility in different formats \\
( Pdf, E-pub, Full Text, Audio) \\
- Unceasing customer service \\
Track the below URL for one-step submission \\
https://juniperpublishers.com/online-submission.php \\
\hline
\end{tabular}

